Revista Brasileira de Meteorologia, v.29, n.1, 55 - 67, 2014

\title{
ESTIMATIVA DO BALANÇO DE ENERGIA UTILIZANDO IMAGENS TM - LANDSAT 5 E O ALGORITMO SEBAL NO LITORAL SUL DE PERNAMBUCO
}

\author{
CÉLIA CRISTINA MACHADO ${ }^{1}$, BERNARDO BARBOSA DA SILVA ${ }^{1}$, MANOEL BANDEIRA DE \\ ALBUQUERQUE ${ }^{2}$, JOSICLÊDA DOMICIANO GALVÍNCIO ${ }^{1}$
}

\author{
${ }^{1}$ Universidade Federal de Pernambuco (UFPE), Departamento de Ciências Geográficas, Recife, PE, Brasil \\ ${ }^{2}$ Universidade Federal da Paraíba (UFPB), Departamento de Fitotecnia e Ciências Ambientais, João Pessoa, \\ PB, Brasil \\ celiamachado.machado@gmail.com, bbdasilva.ufpe@gmail.com,manoel@cca.ufpb.br, josicleda@hotmail. \\ com
}

Recebido Abril de 2012 - Aceito Julho de 2013

\begin{abstract}
RESUMO
As trocas de energia na interface solo-planta-atmosfera, por meio das componentes do balanço de radiação (Rn) e dos fluxos de calor no solo (G), sensível (H) e latente (LE), são essenciais para a modelagem climática e hidrológica que, por sua vez, afetam toda a biosfera. Dessa forma, esta pesquisa teve por objetivos: (1) estimar e comparar o comportamento dos componentes do balanço de energia, usando o algoritmo SEBAL - Surface Energy Balance Algorithm for Land, em diferentes tipos de uso e cobertura do solo e (2) validar o algoritmo. Para isso, foram usadas três imagens TM Landsat 5 de órbita e ponto 214/066, com datas de passagem em 26 de agosto de 2006, 6 de setembro de 2010 e 28 de janeiro de 2011, todas recortadas para enquadrar o litoral sul de Pernambuco. Os resultados mostraram a capacidade do SEBAL de estimar a variabilidade espacial dos diferentes componentes do balanço de energia, com capacidade de distinguir diferentes ocupações do solo. $\mathrm{O}$ cômputo do balanço de energia possibilita observar as formas diferenciadas do uso da energia pelos diferentes tipos de cobertura do solo e verificar aqueles que propiciam melhor conforto térmico. As estimativas da evapotranspiração obtidas pelo algoritmo SEBAL apresentaram uma boa concordância com os resultados obtidos pelo método da FAO-Penman-Monteith demonstrando, dessa forma, a potencialidade da abordagem metodológica escolhida.
\end{abstract}

Palavras-chave: SEBAL, balanço de energia, evapotranspiração.

\begin{abstract}
ASSESSMENT OF ENERGY BALANCE USING TM - LANDSAT 5 DIGITAL IMAGES AND SEBAL ALGORITHM OVER THE SOUTHERN PERNAMBUCO SEACOAST

The energy exchange across soil vegetation-atmosphere interface through the net radiation components $(\mathrm{Rn})$ the soil heat flux $(\mathrm{G})$, sensible heat flux $(\mathrm{H})$ and latent heat flux (LE) are of vital importance for the climatic and hydrologic modeling, which affects all biosphere. The main objectives of this research are: (1) to estimate and compare the several energy balance components behavior, using SEBAL algorithm, under different soil usages; and (2) to validate SEBAL algorithm. In order to make the analysis, three TM - Landsat 5 images, from orbit and point 214/066, of August $26^{\text {th }} 2006$, September $6^{\text {th }} 2010$ and January $28^{\text {th }} 2011$, covering the South Coast of Pernambuco State (Brazil) were used. The results showed the ability of SEBAL to estimate the spatial variability of the different components of energy balance, with the ability to distinguish different soil occupations. The calculation of the energy balance components allows to figure the different forms of energy usages by different soil coverage and to find those that provide better thermal comfort. Estimates of evapotranspiration obtained by the algorithm SEBAL showed a good agreement with the results obtained by the FAOPenman-Monteith, thus demonstrating the potential of this methodological approach.
\end{abstract}

Keywords: SEBAL, energy balance, evapotranspiration. 


\section{INTRODUÇÃO}

Os processos radiativos em superfície interferem significativamente na redistribuição de umidade e de calor no solo e na atmosfera que, por sua vez, afetam o comportamento do tempo, do clima e da biosfera na Terra (Bastiaanssen et al., 1998a; Roerink et al., 2000). As trocas de energia na interface solo-vegetação-atmosfera, por meio das componentes do saldo de radiação (Rn) e dos fluxos de calor no solo $(G)$, sensível (H) e latente (LE), são essenciais para a modelagem climática e hidrológica.

O fluxo de calor latente (LE) representa a perda da água da superfície sob a forma de vapor, podendo ser convertido em evapotranspiração (ET), em unidade de $\mathrm{mm} \mathrm{dia}^{-1}$, nas áreas da agronomia e hidrologia, essenciais no cálculo do balanço hídrico. Já o termo LE, em unidade de $\mathrm{W} \mathrm{m}^{-2}$, é mais usado nos estudos do balanço de energia (BE) da superfície terrestre pelos meteorologistas (Liu, 2007). O estudo da evapotranspiração real (ETr) das áreas agrícolas e da vegetação, em geral, é essencial para a gestão de bacias hidrográficas, para o manejo hídrico da agricultura irrigada e em modelagens meteorológicas e hidrológicas. As estimativas da ET indicam aspectos ecologicamente importantes relacionados com o suprimento de energia, com o balanço hídrico e com a produtividade primária. A variação geográfica da dinâmica água-energia afeta a distribuição, quantidade e duração da fotossíntese e das subsequentes atividades biológicas (O'Brien et al., 2000; Field et al., 2005; O'Brien, 2006).

Adeterminação da evapotranspiração em cultivos agrícolas e em vegetação nativa tem sido amplamente obtida por meio dos métodos do balanço de energia segundo a razão de Bowen (Perez et al., 2008; Nagler et al., 2005; Santos, 2010) e o das correções de vórtices turbulentos (Barr et al., 2006; Hendricks Franssen et al., 2010). No entanto, esses métodos proporcionam resultados pontuais, representativos de pequenas áreas homogêneas, não sendo adequados quando o objetivo é a escala regional. Nesse sentido, as técnicas de sensoriamento remoto têm se demonstrado uma alternativa atraente para estimativa dos fluxos de energia e massa no sistema solo-planta-atmosfera em escala regional, com bom nível de acurácia e a baixo custo.

Dentre os métodos que utilizam imagens de satélites, o SEBAL (Surface Energy Balance Algorithm for Land), proposto por Bastiaanssen (1995), tem sido aplicado com êxito em diversos ecossistemas do globo na obtenção da ET (Haafez et al., 2002; Silva et al., 2005; Bezerra et al., 2008; Teixeira et al., 2009; Matinfar, 2012, Chávez et al., 2012). A ET é determinada com o SEBAL a partir da quantificação do LE, obtido como resíduo da equação do balanço de energia. Esse algoritmo pode ser aplicado em imagens digitais de qualquer sensor orbital que efetue medidas de radiância no visível, infravermelho próximo e termal, tais como: TM - Landsat 5 (Bezerra et al., 2008; Menezes et al., 2011, Anderson et al., 2012), NOAA-AVHRR (Timmermans e Meijerink, 1999; Bastiaanssen e Ali, 2003; Paiva, 2005), MODIS/ Terra/Aqua (Di Long et al., 2010; Santos, 2011; Oliveira, 2012) e ASTER/Terra (Hafeez et al., 2002; Wang et al., 2005).

A determinação do balanço de energia na superfície terrestre envolve duas partes: a primeira consiste em quantificar a energia líquida (Rn) dos fluxos das radiações de onda curta e de onda longa recebida e emitida pela superfície, enquanto a segunda estima os fluxos G, H e LE de utilização da radiação líquida disponível na superfície terrestre (Liu, 2007).

$\mathrm{O}$ saldo de radiação - $\mathrm{Rn}\left(\mathrm{W} \mathrm{m}^{-2}\right)$ de uma superfície representa a quantidade de energia na forma de ondas eletromagnéticas disponíveis para repartir entre os fluxos de energia necessários aos processos de evapotranspiração, aquecimento do ar, aquecimento do solo e fotossíntese. O fluxo de calor no solo - $\mathrm{G}\left(\mathrm{W} \mathrm{m}^{-2}\right)$, por sua vez, representa a fração do balanço de energia transferida por processos de condução ou difusão térmica no solo. $G$ representa a quantidade de energia do Rn utilizada para aquecer o solo e é altamente dependente da condição, textura e ocupação do solo. No SEBAL, G é determinado em função do índice de vegetação por diferença normalizada (NDVI - normalized difference vegetation índex), temperatura da superfície, albedo e Rn.

O cerne do SEBAL, no entanto, é o fluxo de calor sensível - $\mathrm{H}\left(\mathrm{W} \mathrm{m}^{-2}\right)$, obtido com base na teoria de similaridade de MoninObukov através de um processo iterativo levando em consideração as condições de estabilidade atmosférica. H é calculado utilizando dois píxeis na função de âncoras, denominados de píxel quente e píxel frio, que representam valores extremos da ET. No píxel quente assume-se que o fluxo de calor latente $\mathrm{LE} \approx 0$, enquanto, no píxel frio, assume-se que $\mathrm{LE} \approx \mathrm{Rn}-\mathrm{G}$, ou seja, estima-se que o fluxo de calor sensível é igual a zero com gradiente vertical de temperatura do ar também nulo. Assim, no SEBAL, considera-se que o píxel quente (com elevada emitância termal) cria diferenças verticais de temperatura do ar (dT) superiores às superfícies relativamente mais frias e que essas diferenças podem ser expressas em função da temperatura da superfície.

O fluxo de calor latente $-\mathrm{LE}\left(\mathrm{W} \mathrm{m}^{-2}\right)$ é calculado como resíduo da equação geral do balanço de energia, a partir do qual se obtém a fração evaporativa instantânea - FE. Considera-se, ainda, que a FE instantânea representa a FE diária em dias com poucas ou completa ausência de nuvens.

O SEBAL foi concebido para efetuar o balanço de energia em escala regional, tendo por base imagens orbitais e poucos dados complementares de superfície, e para gerar mapas de ET em escalas regional e local em áreas irrigadas de regiões áridas (Bastiaanssen, 1995). No entanto, para melhorar a acurária do algoritmo são necessárias parametrizações de diversas equações para melhor ajustá-las à realidade local da 
região de estudo. Dessa forma, vários autores iniciaram um processo de validação e revisão das várias etapas do SEBAL para áreas particulares, tendo sido validado em diversas campanhas experimentais, por todo o mundo, em áreas irrigadas e em bacias hidrográficas (Bastiaanssen et al., 1998b; Tasumi et al., 2005; Silva et al., 2005; Andrade, 2008; Silva et al., 2008; Teixeira et al., 2009; Santos et al., 2010). Essa validação é realizada por comparação entre os dados estimados e os dados obtidos em campo por medição direta dos fluxos de superfície ou utilizando métodos de medição pontual, tal como o método FAO-Penman-Monteith.

Diante do exposto, esta pesquisa teve por objetivos: (1) avaliar o comportamento dos vários componentes do balanço de energia e da ET obtidos com o SEBAL em áreas de solo exposto, de cultivo de cana-de-açúcar, manguezal e Mata Atlântica na região sul do litoral do estado de Pernambucano e (2) validar o algoritmo com dados da evapotranspiração de cultura - ETc de um cultivo de cana-de-açúcar, estimada pelo método da FAO-Penman-Monteith.

\section{MATERIAL E MÉTODOS}

\section{1 Área de estudo}

A área estudada se localiza na região sul do litoral do estado de Pernambuco, incluindo a foz do rio Formoso e do rio Una e os municípios de Tamandaré e Barreiros. O recorte estudado (ponto superior esquerdo - coordenadas UTM: N9047809, E249004; ponto inferior direito - coordenadas UTM: N9017268, E278944), representado na Figura 1, inclui a reserva biológica de Saltinho, correspondente a um remanescente de Mata Atlântica de 548 ha (verde escuro), uma extensa área de manguezal situada no entorno da foz dos rios Formoso e Una (verde musgo); vastas áreas de cultivo de canade-açúcar (verde claro) que, por constituir uma das atividades econômicas mais importantes da região, ocupa a maior parte da área estudada, e solo exposto (castanho claro), na maioria das vezes, correspondente a bancos de areia e áreas de recente corte da cana-de-açúcar.

O clima, segundo Koppen, é tropical atlântico com precipitações entre 1500 e $1800 \mathrm{~mm}$ (dados do Instituto de Tecnologia de Pernambuco e do Laboratório de Meteorologia de Pernambuco - ITEP/LAMEPE), podendo, em algumas regiões, ultrapassar os $2000 \mathrm{~mm}$. O relevo é do tipo baixada litorânea, com planícies costeiras de origem sedimentar de baixa altitude e predominância de morros e colinas formações onduladas e melonizadas. Na Figura 2 encontra-se a hipsometria da área de estudo realizada através do modelo digital de elevação (MDE) da missão SRTM - Shuttle Radar Topography Mission, refinado pelo TOPODATA com resolução espacial de $30 \mathrm{~m}$, produto 08S36ZN, disponível em: www.dsr. inpe.br/topodata.

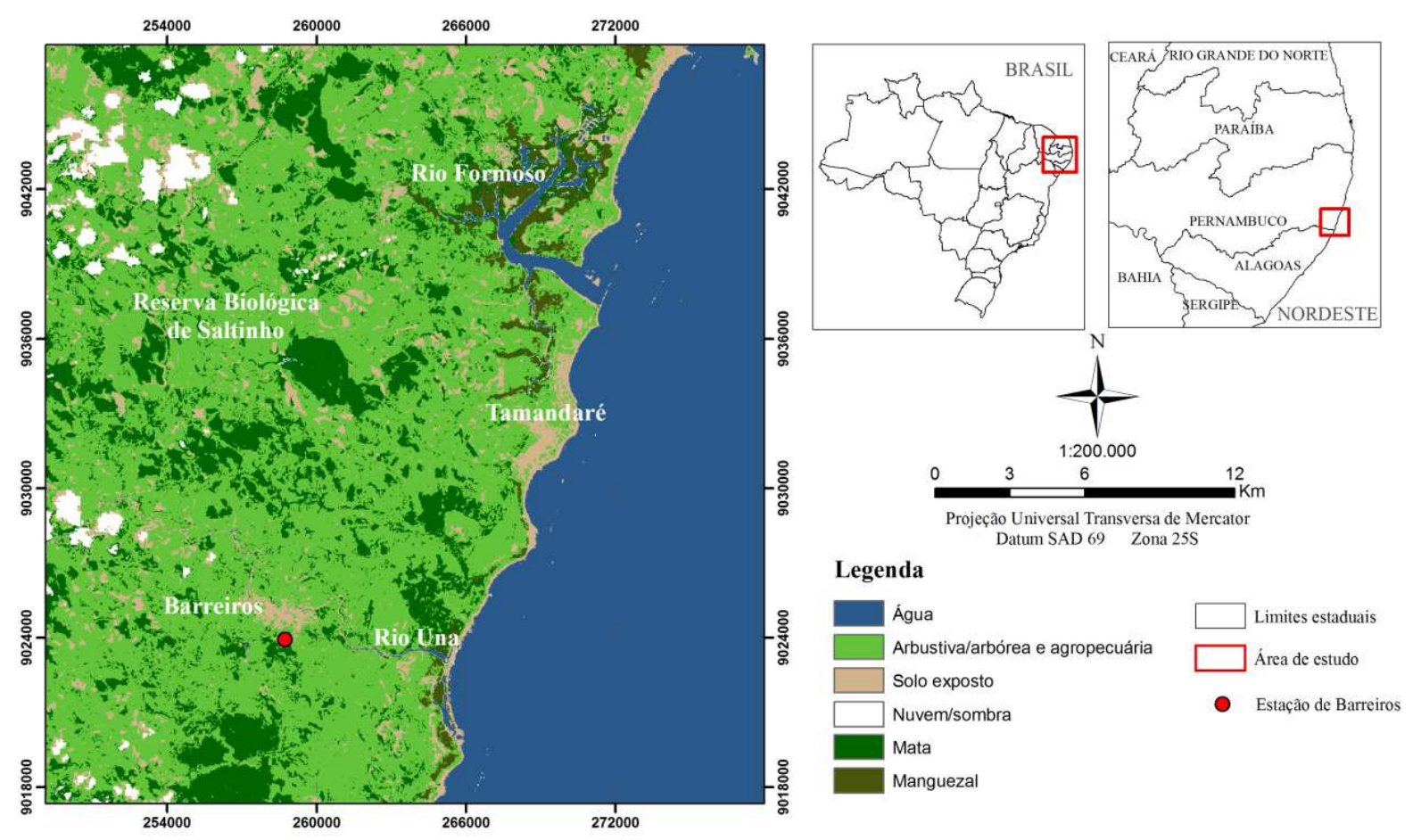

Figura 1 - Uso e cobertura do solo da área de estudo e sua localização em referência ao estado de Pernambuco e ao Brasil. 

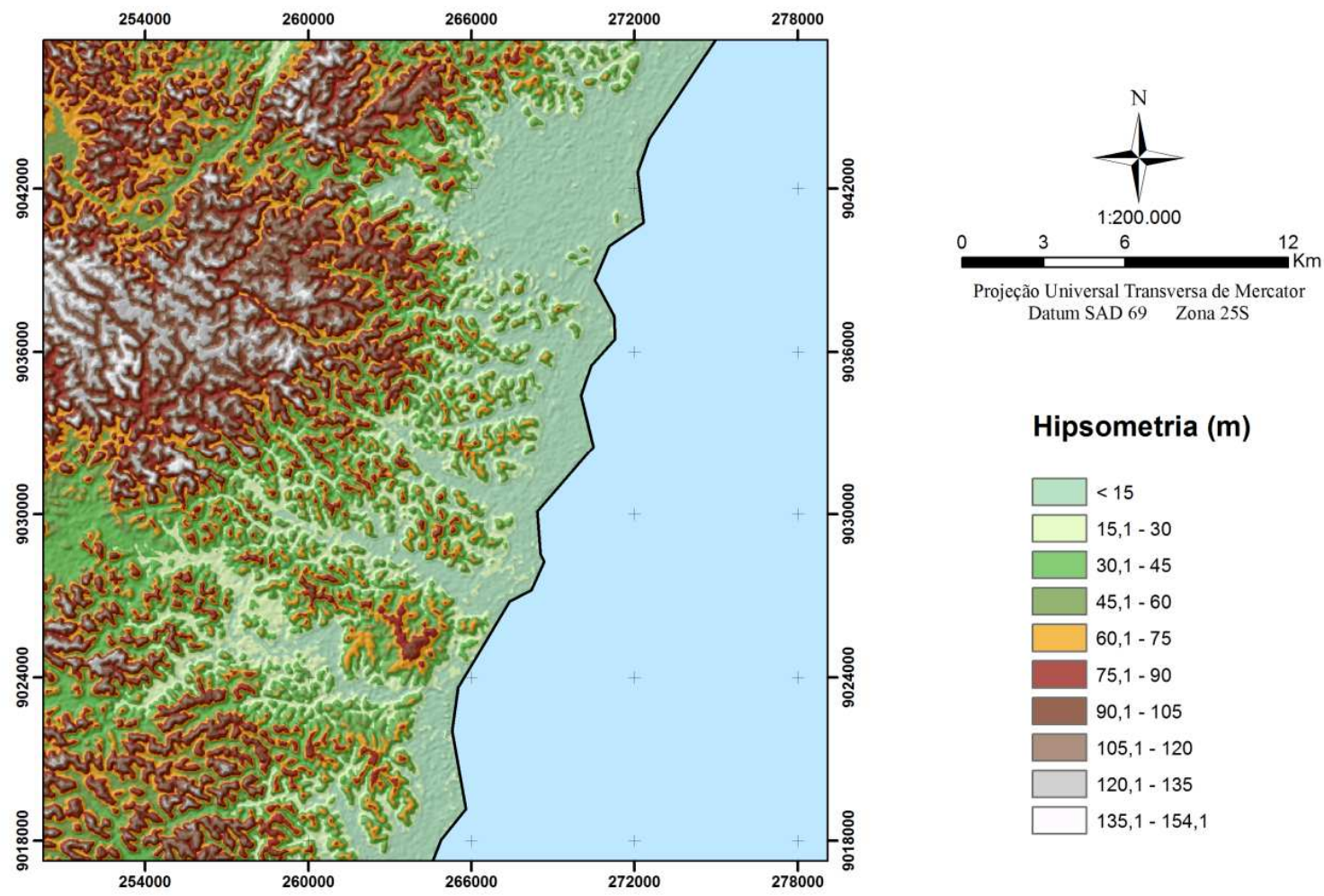

Hipsometria (m)

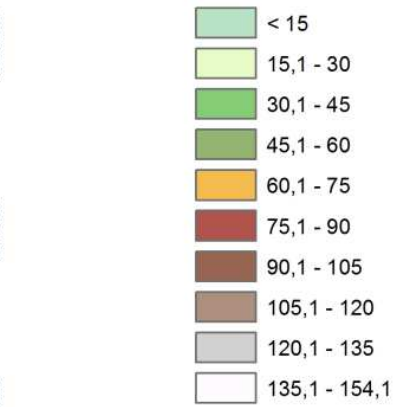

Figura 2 - Hipsometria da área de estudo realizada a partir do modelo digital de elevação (TOPODATA).

\subsection{Processamento das imagens de satélite e dados meteorológicos}

Procedeu-se ao processamento de três imagens TM - Landsat 5, cedidas pelo Instituto Nacional de Pesquisas Espaciais (INPE), da órbita e ponto 214/066 com datas de passagem de 26 de agosto de 2006, 6 de setembro de 2010 e 28 de janeiro de 2011. As imagens foram reunidas e registradas empregando a correção geométrica de modelo polinomial de $1^{\text {a }}$ ordem e 6 pontos de controle, como recomendado por D'Alge (2003). A imagem de referência ortorretificada foi obtida do endereço eletrônico www.landsat.org. O erro do registro foi inferior a um pixel $(30 \mathrm{~m}) \mathrm{em}$ todas as imagens. Posteriormente, as imagens foram recortadas de acordo com os limites da área de estudo. O pré-processamento das imagens de satélite, o cômputo dos diversos componentes do balanço de energia e a montagem final dos mapas temáticos foram realizados utilizando os programas Erdas Imagine 9.3 e ArcGis 9.3.

Os dados meteorológicos utilizados para a estimativa das componentes do balanço de energia e da ET foram obtidos a partir da consulta do arquivo de dados meteorológicos da plataforma de coleta de dados, posto Barreiros (UTM - N9023940, E258720) disponibilizado pelo APAC/ITEP (Agência Pernambucana de Águas e Clima/Instituto de Tecnologia de Pernambuco). A cultura utilizada para validação dos resultados foi a cana-deaçúcar situada próxima à estação. Tratando-se de um cultivo não irrigado, para o cálculo da ET fez-se necessário a obtenção do Ks (coeficiente de estresse) para o dia de cada imageamento de acordo com a metodologia apresentada pela FAO-56 (Allen et al., 1998). Assim, realizaram-se os balanços hídricos para os três imageamentos, considerando o dia 1 aquele precedido por 5 dias com evento acentuado de precipitação ( $>40 \mathrm{~mm}$ ) (Allen et al., 1998) e admitiu-se o nível de depleção de água do solo inicial, metade da água imediatamente disponível (RAW - Readily Available Water) como recomendado em ICMS (2010). Para os dias das três imagens em estudo, o Ks sempre se manteve igual a 1 indicando, portanto, que apesar de não ser irrigada, a precipitação ocorrida antes dos imageamentos foi suficiente para manter a cultura sem estresse hídrico. Dessa forma calculou-se a ETc (igual ao produto entre a evapotranspiração de referência - ETo e o coeficiente de cultura - Kc) no cultivo de cana-de-açúcar próximo à estação, tendo-se utilizado o método da FAO-Penman-Monteith para a estimativa da ETo (Allen et al., 1998). O valores de Kc utilizados para cana-soca foram conforme recomendado pela FAO24 (Doorenbos e Pruitt, 1977). De acordo com estes autores, cana com 1-2 meses (caso da cana na imagem de 28-01-2011) apresenta 25 a 50\% de cobertura do solo e um Kc igual a 0,8. Já para cana com 10 - 11 meses 
(caso da cana nas imagens de 26-08-2006 e de 6-09-2010), de acordo com os mesmos autores, a cultura encontra-se no início da maturação e o seu Kc é também 0,8 (Tabela 1).

\subsection{Método SEBAL}

De acordo com o algoritmo SEBAL, a evapotranspiração é obtida após conversão do valor instantâneo de fluxo de calor latente - LE (W m $\left.{ }^{-2}\right)$, em ET (mm) total das $24 \mathrm{~h}$. O LE é obtido como resíduo da equação clássica do balanço de energia à superfície:

$$
\mathrm{LE}=\mathrm{Rn}-\mathrm{H}-\mathrm{G}
$$

onde Rn é o saldo de radiação, LE é a densidade de fluxo de calor latente, $\mathrm{H}$ é a densidade de fluxo de calor sensível e $\mathrm{G}$ é a densidade de fluxo de calor no solo, todos em $\mathrm{W} \mathrm{m}^{-2}$.

Rn é uma variável fundamental para o cômputo do balanço de energia e foi obtida conforme esquema ilustrado na Figura 3, que envolve a calibração radiométrica, cálculo da reflectância, albedo, índices de vegetação, emissividade e temperatura da superfície (Silva et al., 2011).

G pode ser obtido segundo equação empírica desenvolvida por Bastiaanssen (2000) para valores próximos ao meio-dia:

$$
\mathrm{G}=\left[\operatorname{Ts}(0,0038+0,0074 \alpha)\left(1-0,98 \mathrm{NDVI}^{4}\right)\right] \operatorname{Rn}
$$

onde Ts é a temperatura da superfície $\left({ }^{\circ} \mathrm{C}\right), \alpha$ é o albedo da superfície e NDVI é o índice de vegetação por diferença normalizada, todos calculados píxel a píxel. Para corpos de água assumiu-se que $\mathrm{G}=0,5 \mathrm{Rn}$, segundo Allen et al. (2007). Reconhece-se que um corpo de água pode apresentar valores de NDVI ligeiramente superiores a zero, motivo de se considerar, neste estudo, píxeis com presença de água quando NDVI $<0,05$.

O fluxo de calor sensível - H, o cerne do SEBAL, foi obtido através de um processo iterativo. Inicialmente, utiliza-se a velocidade do vento $\mathrm{u}\left(\mathrm{m} \mathrm{s}^{-1}\right)$ e a altura média da vegetação no entorno da estação $h(m)$. Nesta pesquisa a altura média da vegetação era de $0,2 \mathrm{~m}$, o que possibilitou estimar o coeficiente de rugosidade ao transporte de momentum - Zom (m) (Equação 3). Sendo possível obter a velocidade de fricção $\mathrm{u}^{*}\left(\mathrm{~m} \mathrm{~s}^{-1}\right)$ segundo a expressão (Equação 4) de acordo com (Allen et al., 2002; Silva e Bezerra, 2006; Mendonça, 2007):

$$
\begin{aligned}
& \text { Zom }=0,12 \mathrm{~h} \\
& \mathrm{U}_{*}=\frac{\mathrm{K} \times \mathrm{U}_{\mathrm{x}}}{\ln \left(\mathrm{Z}_{\mathrm{x}} / \mathrm{Z}_{\mathrm{om}}\right)}
\end{aligned}
$$

onde k é a constante de Von Karman $(0,41)$, u é a velocidade do vento a $\mathrm{X}$ metros de altura e $\mathrm{Z}$ é a altura (m) em que ocorreu a medição da velocidade do vento.

Considerando a atmosfera em equilíbrio neutro e o perfil logaritmo do vento, projetou-se a velocidade do vento a $200 \mathrm{~m}$ (altura de mistura), altura em que a rugosidade da superfície já não mais interfere na velocidade do vento, admitindo-se, portanto, que naquele nível essa velocidade é espacialmente constante. Assim, a velocidade de fricção de cada píxel é obtida segundo a equação (Allen et al., 2002; Silva e Bezerra, 2006; Mendonça, 2007):

$$
\mathrm{U}_{*}=\frac{\mathrm{K} \times \mathrm{U}_{200}}{\ln \left(200 / \mathrm{Z}_{\text {om }}\right)}
$$

em que $\mathrm{u}_{200}\left(\mathrm{~m} \mathrm{~s}^{-1}\right)$ é a velocidade do vento a $200 \mathrm{~m} \mathrm{e}_{\mathrm{om}}$ (m) é obtido píxel a píxel em função da imagem do índice de vegetação por ajustamento do solo (SAVI - soil adjusted vegetation index):

$$
Z_{\text {om }}=\exp (-5,809+5,62 \times S A V I)
$$

De posse dos valores de $u^{*}$, estimou-se a resistência aerodinâmica ao transporte de momentum - $\mathrm{r}_{\mathrm{ah}}\left(\mathrm{s} \mathrm{m}^{-1}\right)$ segundo a equação (Allen et al., 2002; Silva e Bezerra, 2006; Mendonça, 2007):

$$
\mathrm{r}_{\mathrm{ah}}=\frac{\ln \left(\mathrm{Z}_{2} \times \mathrm{Z}_{1}\right)}{\mathrm{U}_{*} \mathrm{~K}}
$$

onde z1 e z2 são as alturas acima da superfície, normalmente $0,1 \mathrm{~m}$ e $2,0 \mathrm{~m}$, respectivamente.

O cômputo da diferença da temperatura do ar em dois níveis próximos à superfície foi feito admitindo-se que essa diferença pode ser obtida em função da temperatura radiométrica de cada pixel:

$$
\mathrm{dT}=\mathrm{a}+\mathrm{bTs}
$$

Tabela 1 - Valores de Kc para cana-soca.

\begin{tabular}{ccc}
\hline Idade da cana (meses) & Estágio de desenvolvimento da cultura & Kc \\
\hline $\mathbf{0 - 1}$ & Do plantio até $25 \%$ de cobertura do solo & 0,55 \\
$\mathbf{1 - 2}$ & De 25 a $50 \%$ de cobertura do solo & 0,80 \\
$\mathbf{2 - 2 , 5}$ & De 50 a $75 \%$ de cobertura do solo & 0,90 \\
$\mathbf{2 , 5 - 4}$ & De 75 a $100 \%$ de cobertura do solo & 1,00 \\
$\mathbf{4 - 1 0}$ & Cobertura total do solo & 1,05 \\
$\mathbf{1 0 - 1 1}$ & Início da maturação & 0,80 \\
$\mathbf{1 1 - 1 2}$ & Maturação & 0,60 \\
\hline
\end{tabular}

Fonte: Doorenbos e Pruitt (1977). 


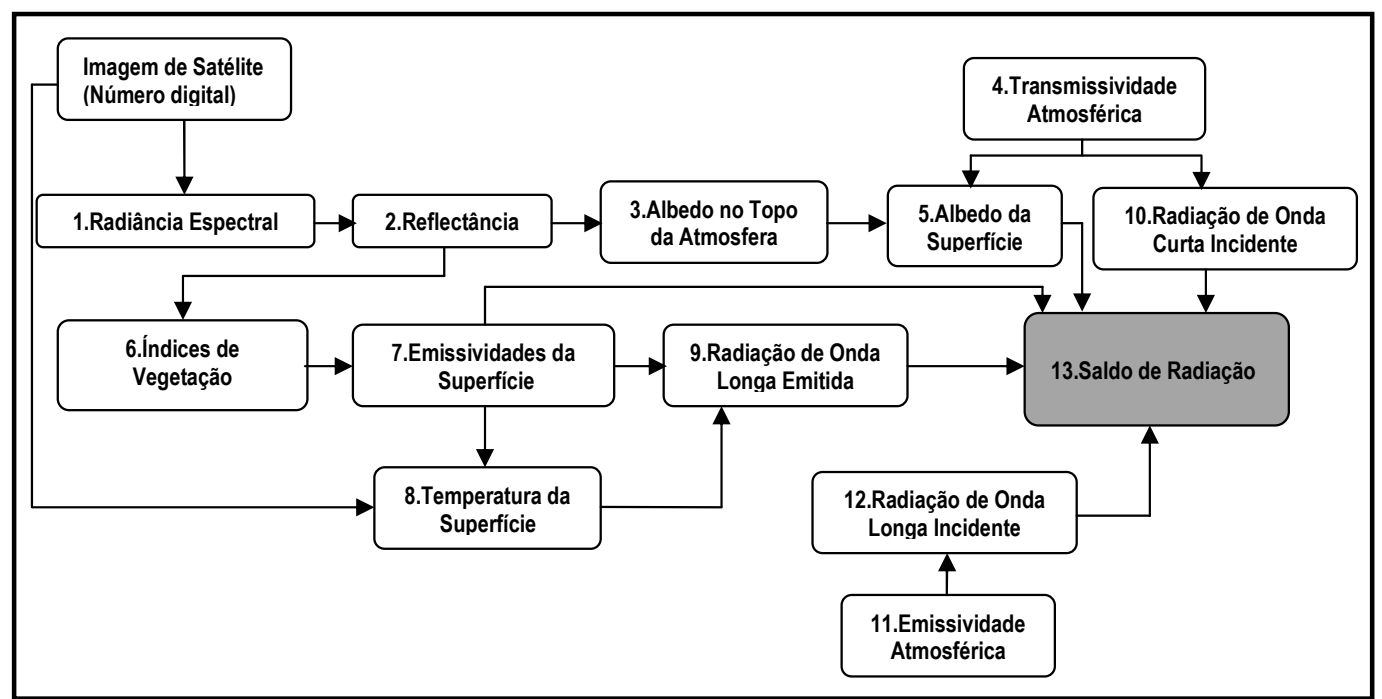

Figura 3 - Diagrama representativo das etapas computacionais para obtenção do saldo de radiação (Rn) a partir do algoritmo SEBAL.

onde a e b são coeficientes obtidos com base das condições verificadas nos píxeis âncoras e Ts éa temperatura de cada píxel $\left({ }^{\circ} \mathrm{C}\right)$.

$\mathrm{O}$ píxel frio foi escolhido no centro do rio Formoso (UTM: N9040647, E267831), onde se assumiu que $\mathrm{H}=0 \mathrm{e}$, consequentemente, $\mathrm{dT}=0$ e a densidade de fluxo de calor latente foi calculada por $\mathrm{LE}=\mathrm{RN}-\mathrm{G}$. Já o píxel quente foi identificado em área com baixa cobertura vegetal (IAF $<0,2)$ e onde se assumiu LE $=0$. Dessa forma, o valor de $\mathrm{H}$ nesse píxel é dado por:

$$
R n-G=\frac{\rho_{a r} c_{p}(a+b T s)}{r_{a h}}
$$

onde $\rho_{\mathrm{ar}}\left(\mathrm{kg} \mathrm{m}^{-3}\right)$ é a massa específica do ar, $\mathrm{c}_{\mathrm{p}}$ é o calor específico a pressão constante $\left(\mathrm{J} \mathrm{kg}^{-1} \mathrm{~K}^{-1}\right)$ e Ts $\left({ }^{\circ} \mathrm{C}\right), \mathrm{Rn}\left(\mathrm{W} \mathrm{m}^{-2}\right)$ e $\mathrm{G}\left(\mathrm{W} \mathrm{m}^{-2}\right)$ foram obtidos no píxel quente da imagem. Com base nesses valores obteve-se:

$$
a+b T s=\frac{r_{a h}(R n-G)}{\rho_{a r} c_{p}}
$$

Como no píxel frio $\mathrm{dT}=0$, ou seja, $\mathrm{dT}=\mathrm{a}+\mathrm{b} \mathrm{Ts}=0$, tem-se um sistema com duas equações e duas incógnitas, possibilitando o cálculo de a e b. Logo, pode-se obter H, segundo a equação:

$$
\mathrm{H}=\frac{\rho_{\mathrm{ar}} \mathrm{c}_{\mathrm{p}}(\mathrm{a}+\mathrm{bTs})}{\mathrm{r}_{\mathrm{ah}}}
$$

Os valores de $\mathrm{H}$ obtidos não representam adequadamente o fluxo de calor sensível de cada píxel, por serem valores iniciais de um processo iterativo onde, nas etapas seguintes, é considerada a condição de estabilidade de cada píxel. Para isso, foi utilizado o comprimento de Monin-Obukhov para identificar a condição de estabilidade atmosférica de cada píxel e efetivar a correção da estabilidade para o transporte de momentum e calor sensível. Esses últimos, uma vez determinados, possibilitaram corrigir a velocidade de fricção e, em consequência, a resistência aerodinâmica ao transporte de calor. Depois de obtidos os valores desses parâmetros, calculou-se novamente dT e, posteriormente, $\mathrm{H}$ com os novos valores de $\mathrm{r}_{\mathrm{ah}}$ (Bastiaanssen, 1995; Allen et al., 2002; Silva e Bezerra, 2006; Mendonça, 2007). Esses passos foram repetidos até verificada estabilidade dos valores de dT e de $r_{a h}$ no píxel quente. Mediante esse procedimento, foram realizadas sete iterações (Figura 4).

Depois de obtido LE a partir da Equação 1, a ET é calculada com base na fração evaporativa instantânea $\left(\mathrm{FE}_{\mathrm{i}}\right)$, definida como a razão entre LE e $(\mathrm{Rn}-\mathrm{G})$. De acordo com vários estudos, $\mathrm{FE}_{\mathrm{i}}$ é igual a $\mathrm{FE}_{24 \mathrm{~h}}$. Dessa forma, tem-se:

$$
F E_{i}=\left(\frac{L E}{R n-G}\right)=F E_{24 h}=\frac{L E_{24 h}}{R n_{24 h}}
$$

Como se admite que $\mathrm{G}_{24 \mathrm{~h}}=0, \mathrm{LE}_{24 \mathrm{~h}}$ será dada por:

$$
\mathrm{LE}_{24 \mathrm{~h}}=\mathrm{FE}_{\mathrm{i}} \times \mathrm{Rn}_{24 \mathrm{~h}}
$$

onde Rn24h é dada pela seguinte expressão:

$$
\mathrm{Rn}_{24 \mathrm{~h}}=\mathrm{Rs}_{24 \mathrm{~h}}(1-\text { albedo })-110 \times \tau \mathrm{sw}_{\downarrow_{24 \mathrm{~h}}}
$$

$\mathrm{Rs}_{24 \mathrm{~h}}$ corresponde ao total de radiação solar obtida ao longo do dia e foi obtida com dado da estação enquanto que a $\tau \mathrm{SW}_{24 \mathrm{~h}}$ foi obtida por:

$$
\tau \mathrm{SW}_{\downarrow_{24 \mathrm{~h}}}=\mathrm{Rs}_{24 \mathrm{~h}} / \mathrm{Rs}_{\text {toa }}
$$

em que $\mathrm{Rs}_{\text {toa }}$ é a radiação solar incidente no topo da atmosfera e é calculada a partir da latitude da estação e do número sequencial do ano. Por fim, a conversão da $\mathrm{LE}_{24 \mathrm{~h}}$ em ET_24h (mm dia $\left.{ }^{-1}\right)$ é dada por:

$$
\text { ET_24h }=\text { LE24h } \times \text { 86,4/2450 }
$$




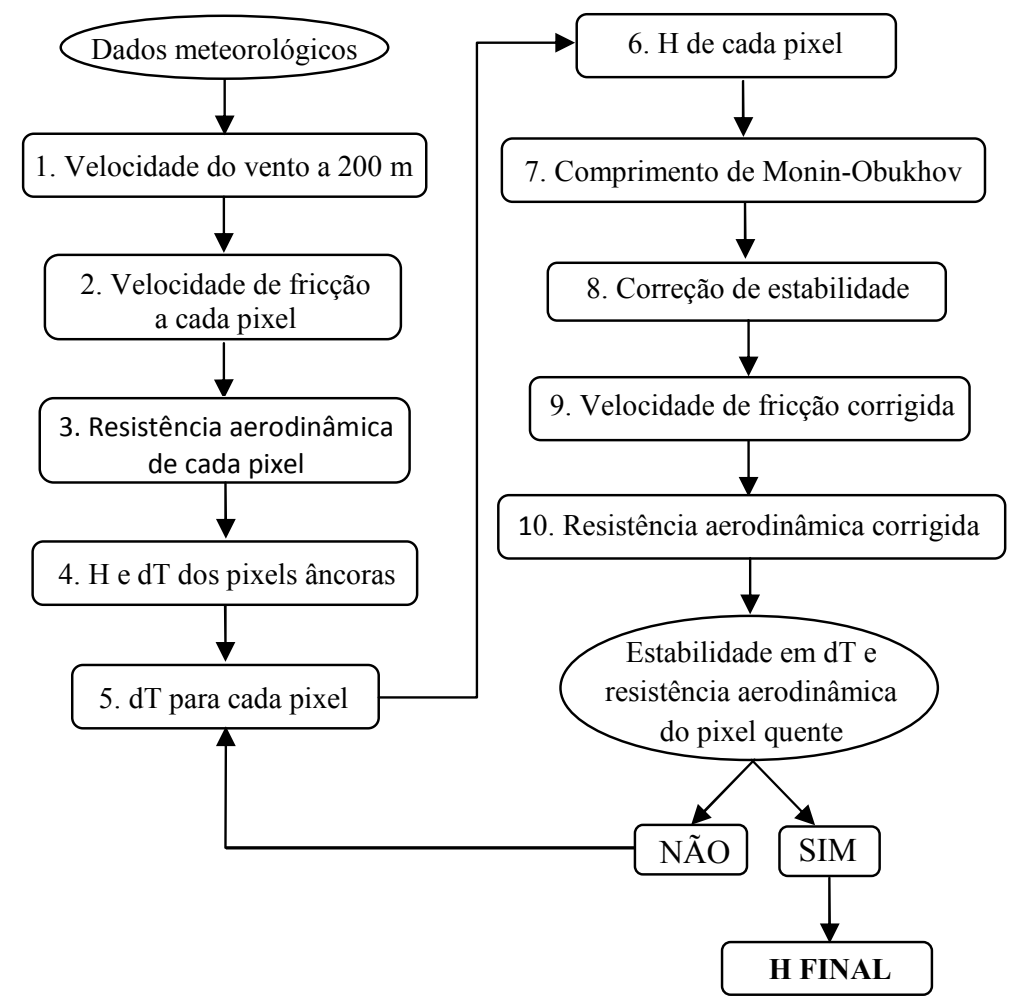

Figura 4 - Fluxograma das etapas computacionais do processo iterativo para a obtenção do fluxo de calor sensível (H) segundo o algoritmo SEBAL.

\section{4 - Análise Comparativa}

A comparação entre a ETc - obtida pelo produto da ETo (FAO-Penman-Monteith) e do Kc, e a ET estimada pelo SEBAL foi feita mediante o cálculo dos erros absoluto e relativo, de acordo com as seguintes expressões:

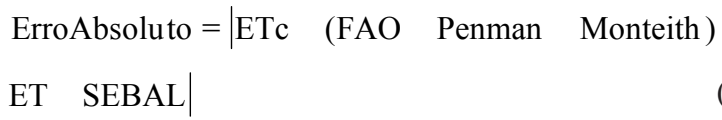

Erro Re lativo $=$

$\frac{\text { ETc } \quad \text { (FAO Penman Monteith) ET SEBAL }}{\text { ETc } \quad(\text { FAO Penman Monteith })} \times 100 \%$

\section{RESULTADOS E DISCUSSÃO}

\subsection{Componentes do balanço de energia}

Nas Figuras 5, 6 e 7 encontram-se representados os valores médios dos componentes do balanço de energia (BE) obtidos, para cada um dos dias estudados, em quatro tipos de cobertura do solo: solo exposto, cana-de-açúcar, manguezal e mata Atlântica. Os valores obtidos correspondem à média dos píxeis de dois recortes distintos de cada um dos alvos em estudo, em que cada recorte apresentava 4x4 píxeis (cerca de 1,5 ha).

Observa-se que o Rn da reserva de Saltinho apresentou os valores mais elevados, variando entre $600 \mathrm{~W} \mathrm{~m}^{-2}$ na imagem de agosto de 2006 e $750 \mathrm{~W} \mathrm{~m}^{-2}$ na de janeiro de 2011, seguido do manguezal, com valores próximos. Bezerra et al. (2008) encontraram valores idênticos para a reserva florestal da Chapada do Araripe, que corresponde a uma área de caatinga densa e preservada. O solo exposto apresentou os menores valores de $\mathrm{Rn}$, variando entre $450 \mathrm{em} 2006$ e $600 \mathrm{~W} \mathrm{~m}^{-2}$ em 2011. Valores em torno de $420 \mathrm{~W} \mathrm{~m}^{-2}$ foram encontrados em solo exposto por Silva et al. (2005) e Giongo (2008). Esses menores valores de Rn devem-se aos maiores valores de albedo e da temperatura da superfície, verificados nas áreas de solo exposto que, em consequência, reduzem o saldo de radiação. Uma vez que mais energia é devolvida de volta para o espaço, menos energia fica disponível para os processos bio-físico-químicos da superfície. Comportamento contrário ocorre com a vegetação densa, que absorve maior porcentagem das ondas curtas incidentes.

Observa-se que, em todos os alvos analisados, os valores de $\mathrm{Rn}$ foram superiores na imagem de 2011. Esse comportamento deve-se, em parte, ao solo se encontrar mais úmido em janeiro de 2011 em função da intensa precipitação verificada. De acordo com dados das estações de Barreiros e Sirinhaém, registrou-se precipitação de $53 \mathrm{~mm}$ nos cinco dias que antecederam o 


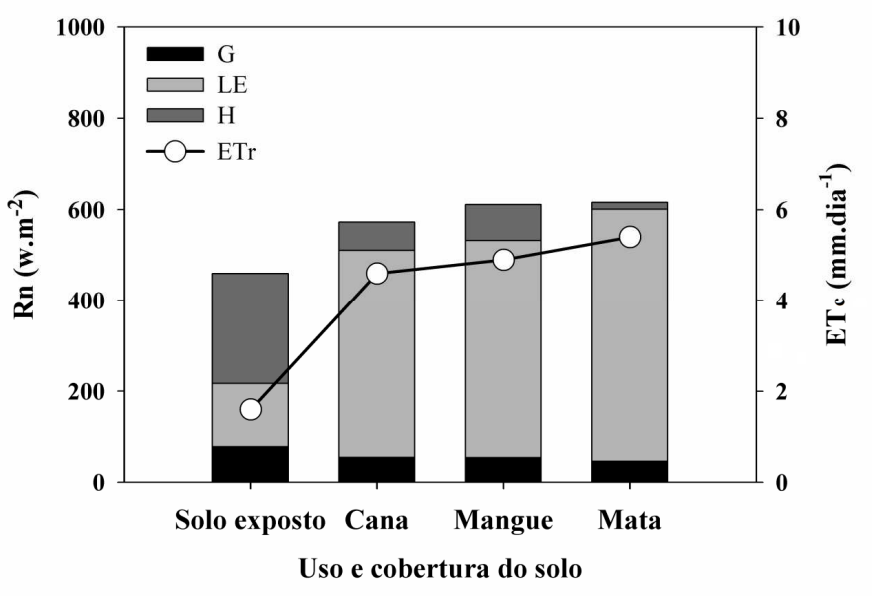

Figura 5 - Variação dos valores dos componentes do balanço de energia e da ETc em quatro diferentes coberturas do solo, no dia 26 de agosto de 2006.

imageamento e $240 \mathrm{~mm}$ ao longo dos 30 dias precedentes (Posto Barreiros - Tabela 2). Em solo mais úmido, o albedo é menor, aumentando a energia líquida dos fluxos das radiações de onda curta e onda longa recebida na superfície (Giongo, 2008). O Rn foi superior em janeiro de 2011, também devido à sazonalidade da radiação solar, ou seja, em função da quantidade de radiação de onda longa incidente nas áreas de estudo que, em janeiro, é substancialmente superior aos valores que ocorrem nos meses de agosto e setembro, e também como resultado da resposta da vegetação à sua fenologia, como é o caso da cana-de-açúcar.

Os valores de $\mathrm{G}$ variaram entre 40 e $55 \mathrm{~W} \mathrm{~m}^{-2}$ no manguezal e na mata Atlântica, correspondendo a valores entre 6 e $9 \%$ do Rn. Superiores foram os valores de G encontrados na cana, em torno de 55 e $70 \mathrm{~W} \mathrm{~m}^{-2}$ (cerca de $10 \%$ do Rn) e no solo exposto, superior a $80 \mathrm{~W} \mathrm{~m}^{-2}$ (em torno de $17 \%$ do $\mathrm{Rn}$ ). Esses resultados significam que mais energia líquida é usada no aquecimento do solo nas culturas de cana e em solo exposto. Como se pode observar na Figura 7, outro efeito da intensa precipitação ocorrida em janeiro de 2011 foi uma diminuição significativa da porcentagem de Rn usada pelo $\mathrm{G}$ em solo exposto $(13 \%)$.

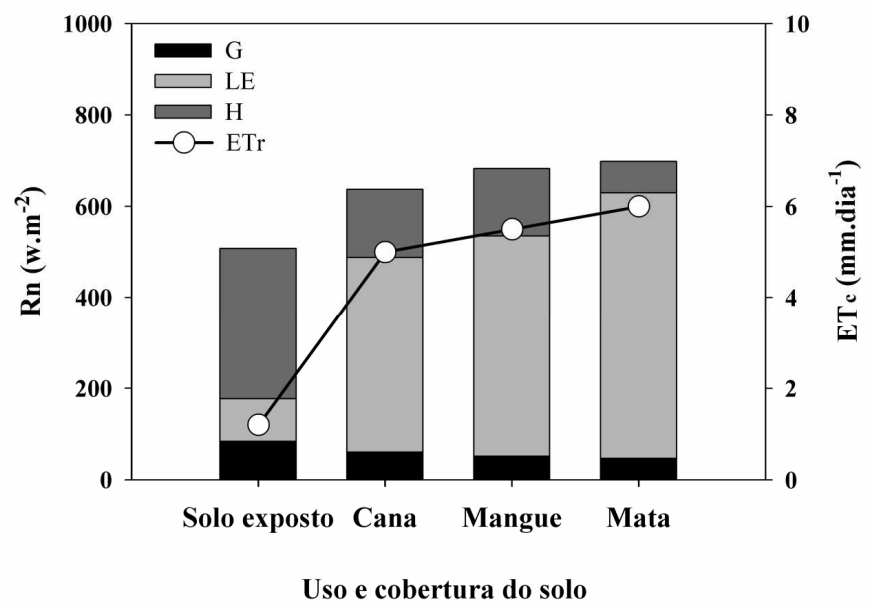

Figura 6 - Variação dos valores dos componentes do balanço de energia e da ETc em quatro diferentes coberturas do solo, no dia 6 de setembro de 2010 .

$\mathrm{H}$ foi superior nas áreas de solo exposto com valores entre 250 e $350 \mathrm{~W} \mathrm{~m}^{-2}$, correspondendo a 50-60\% do Rn e na área de cana com valores entre 50 e $150 \mathrm{~W} \mathrm{~m}^{-2}$ ( 15 a $25 \%$ do Rn). LE foi superior na mata Atlântica, com valores entre 550 e $650 \mathrm{~W} \mathrm{~m}^{-2}$, correspondendo a $80-90 \%$ do $\mathrm{Rn}$, enquanto que o solo exposto apresentou os menores valores. Dessa forma, constata-se que a mata Atlântica e o manguezal utilizam uma maior porcentagem do Rn no processo de perda de água na superfície sob a forma de vapor (LE), enquanto o solo exposto utiliza uma maior porcentagem do Rn nos processos de aquecimento do ar $(\mathrm{H})$. Esse comportamento das diferentes componentes do BE justifica o maior conforto térmico encontrado nas zonas de manguezal e mata Atlântica. O comportamento do LE e do H da cana-deaçúcar variou em função da época do ano, do estado fenológico da cultura e da umidade do solo.

\subsection{Evapotranspiração}

$\mathrm{Na}$ Figura 8 estão representadas as imagens da ET para os dias estudados. As áreas de cor vermelha representam valores de ET menores do que 2,0 $\mathrm{mm} \mathrm{dia}^{-1}$,

Tabela 2 - Dados de precipitação dos postos de Barreiros e Sirinhaém dos 5, 10, 20 e 30 dias antes do imageamento.

\begin{tabular}{llcccc}
\hline & & \multicolumn{4}{c}{ Precipitação antes do imageamento (mm) } \\
& Posto & $\mathbf{5}$ dias & $\mathbf{1 0}$ dias & $\mathbf{2 0}$ dias & $\mathbf{3 0}$ dias \\
\hline \multirow{2}{*}{$\mathbf{2 0 0 6 - 0 8 - 2 6}$} & Barreiros & 0 & 4,1 & 72,4 & 107 \\
& Sirinhaém & 2,6 & 4,8 & 76,3 & 90,7 \\
\multirow{2}{*}{$\mathbf{2 0 1 0 - 0 9 - 0 6}$} & Barreiros & --- & --- & --- & --- \\
& Sirinhaém & 23 & 39,8 & 159 & 222 \\
\multirow{2}{*}{$\mathbf{2 0 1 1 - 0 1 - 2 8}$} & Barreiros & 53,1 & 169,6 & 229 & 240,2 \\
& Sirinhaém & 55,5 & 119,5 & 197,3 & 209,5 \\
\hline
\end{tabular}

Fonte: Doorenbos e Pruitt (1977). 


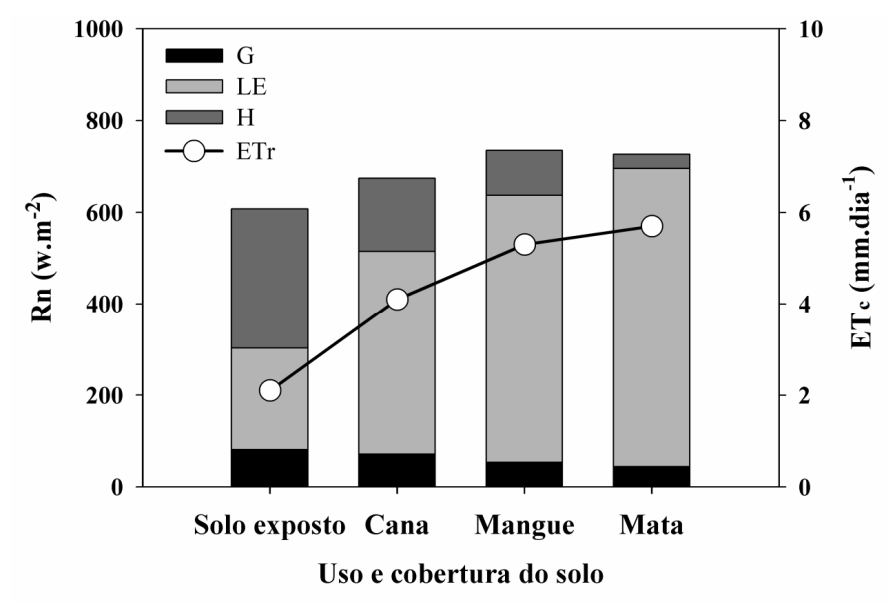

Figura 7 - Variação dos valores dos componentes do balanço de energia e da ETc em quatro diferentes coberturas do solo, no dia 28 de janeiro de 2011.

que correspondem a áreas de solo exposto, bancos de areia e/ou vegetação muito rala. Resultados muito próximos foram encontrados no Cariri do estado do Ceará por Bezerra et al. (2008) e por Wang et al. (2005) em áreas de deserto e vegetação esparsa no estado americano do Novo México. Por outro lado, as áreas em azul-escuro correspondem a valores de ET superiores a 5,5 $\mathrm{mm} \mathrm{dia}^{-1}$. Observa-se que esses valores concentram-se na reserva biológica de Saltinho, em corpos de água e nas áreas sombreadas por nuvens. Os maiores índices de vegetação (IAF > 3) encontrados na mata da reserva de Saltinho justificam os valores elevados de ET encontrados. A cana-de-açúcar, além de apresentar um menor índice de vegetação (IAF $\approx 2$ ), é uma planta com ciclo metabólico de quatro carbonos (tipo $\mathrm{C} 4$ ) que apresenta uma maior eficiência de uso da água (Larcher, 2000) e, por isso, perde menos água por evapotranspiração.

A ET variou bastante entre as imagens estudadas nas áreas de solo exposto e nas ocupadas com cultivos de canade-açúcar. Em janeiro de 2011, a cultura da cana-de-açúcar apresentava-se com um a dois meses de plantada, enquanto que, em agosto de 2006 e setembro de 2010, apresentava-se com cerca de 10-11 meses. Dessa forma, em janeiro de 2011, a cana-de-açúcar encontra-se em fase fenológica inicial, não cobrindo totalmente o solo, justificando-se os menores valores de ET observados (em torno de $4 \mathrm{~mm}$ ), que provavelmente teriam sido ainda menores, na ausência das intensas chuvas que antecederam o imageamento (Gomes et al., 2009).

\subsection{Validação do SEBAL}

Na Tabela 3 faz-se a comparação entre a ETc estimada pelo método FAO-Penman-Monteith e a ET pelo SEBAL, utilizando como referência um cultivo de cana-de-açúcar situado numa área próxima à estação. Observa-se que os erros absolutos e relativos foram baixos, sendo que, em setembro de 2010 , obteve-se a pior estimativa, com $0,5 \mathrm{~mm} \mathrm{dia}^{-1}$ de erro absoluto e $10,8 \%$ de erro relativo. A melhor estimativa foi obtida na imagem de agosto de 2006 com apenas $1,43 \%$ de erro relativo. Comparando com resultados obtidos por outros autores conclui-se que os resultados obtidos nesta pesquisa foram muito satisfatórios. Trezza (2002), após comparar medidas lisimétricas e as estimativas do SEBAL, encontrou erros absolutos inferiores a $1 \mathrm{~mm} \mathrm{dia}^{-1}$. Wang et al. (2005) obtiveram resultados ainda mais satisfatórios, com erros absolutos em torno de $0,5 \mathrm{~mm} \mathrm{dia}^{-1}$. Erros relativos entre 4 e $10 \%$ foram encontrados por Bezerra et al. (2008), quando compararam os resultados obtidos com a razão de Bowen e com o SEBAL em cultura de mamona e algodão na mesorregião do Cariri.

O algoritmo SEBAL apresenta algumas limitações devido ao método empírico muito simples de correção atmosférica que utiliza para estimar o albedo: aplicações a sensores óticos que incluam a banda termal, como viabilizados em imagens Landsat e Modis, em cenas não afetadas por nuvens (Bastiaanssen et al., 2012), a atmosfera precisa ter baixa carga de aerossol e as funções de correção atmosférica restringem-se à transmitância, que varia apenas com a altura e é imprópria para correção por bandas. Essas limitações resultam, de acordo com Tasumi et al. (2008), na redução da acurácia do balanço de radiação estimado em 15\%. Considerando as limitações do algoritmo, os mesmos autores definiram empiricamente as funções de correção atmosférica por bandas. $\mathrm{O}$ método foi incorporado no METRIC, um aprimoramento do SEBAL apresentado por Allen et al. (2007), onde se efetua correção atmosférica em cada uma das bandas espectrais do TM - Landsat 5 combinadas para

Tabela 3 - Evapotranspiração real diária da cultura de cana-de-açúcar pela técnica FAO-Penman-Monteith, ET pelo algoritmo SEBAL e os valores de erros absoluto e relativo.

\begin{tabular}{|c|c|c|c|c|c|}
\hline $\begin{array}{c}\text { Dia do } \\
\text { Ano }\end{array}$ & Cultura & $\begin{array}{c}\text { ET } \\
\text { SEBAL } \\
\left(\mathrm{mm} \mathrm{dia}^{-1}\right)\end{array}$ & $\begin{array}{c}\text { ETc } \\
\text { FAO-Penman- } \\
\text { Monteith }\left(\mathrm{mm} \mathrm{dia}^{-1}\right)\end{array}$ & $\begin{array}{c}\text { Erro } \\
\text { Absoluto (mm } \\
\left.\text { dia }^{-1}\right)\end{array}$ & $\begin{array}{c}\text { Erro Relativo } \\
(\%)\end{array}$ \\
\hline 28 & Cana-de-açúcar & 4,14 & 4,46 & 0,32 & 7,17 \\
\hline 238 & Cana-de-açúcar & 4,13 & 4,19 & 0,06 & 1,43 \\
\hline 249 & Cana-de-açúcar & 5,13 & 4,63 & 0,50 & 10,80 \\
\hline
\end{tabular}



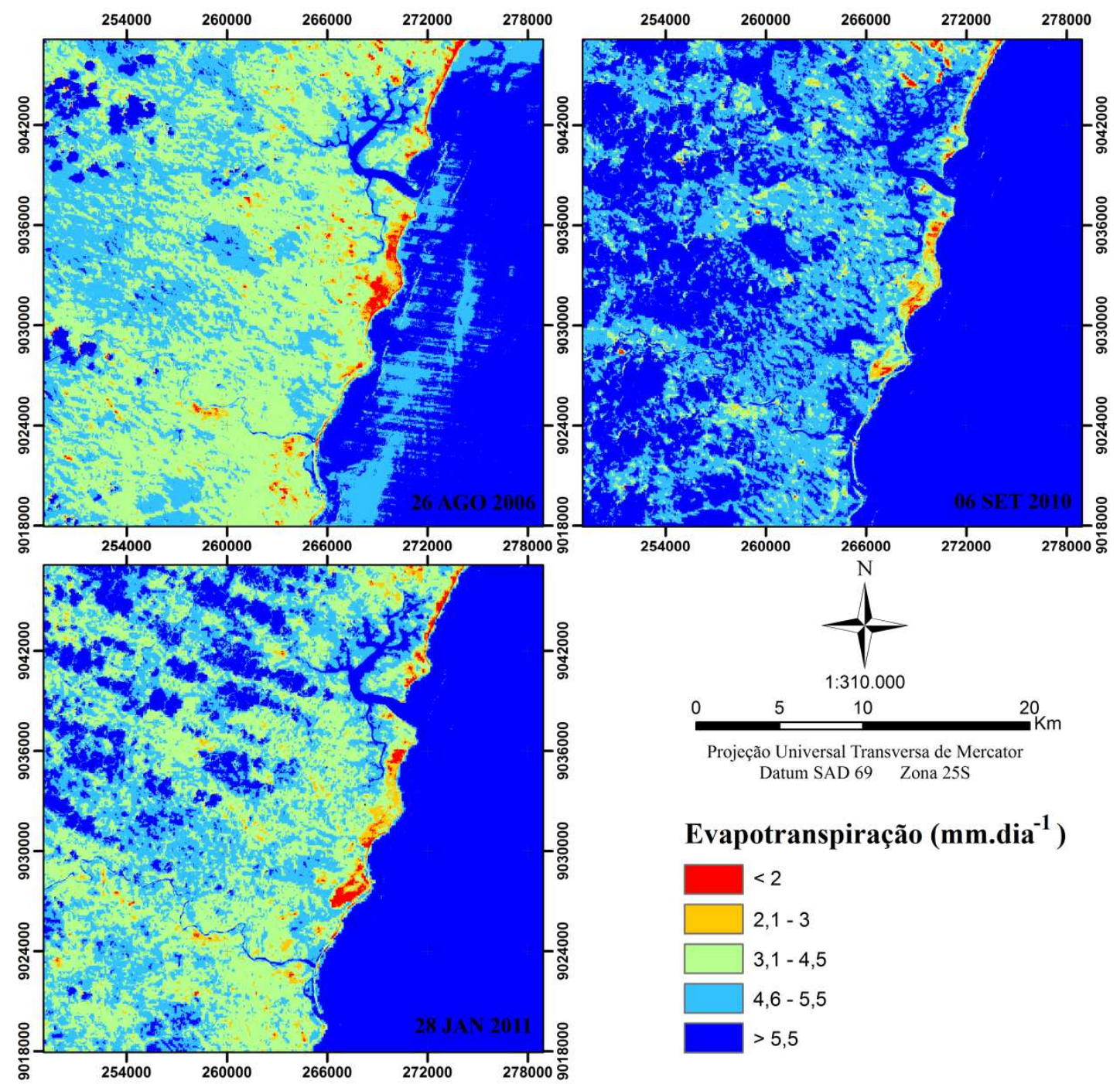

Figura 8 - Imagens da ET diária na área de estudo para os dias 26 de agosto de 2006, 06 de setembro de 2010 e 28 de janeiro de 2011.

obtenção do albedo da superfície, resultando no melhoramento das estimativas do balanço de radiação e, em consequência, das estimativas da ET. Outras limitações do algoritmo são: a subjetividade na escolha dos píxeis âncoras; em regiões montanhosas, depende de modelos digitais de elevação, por vezes imprecisos; erros na temperatura da superfície estimada têm grande impacto nas estimativas de $\mathrm{H}$; os efeitos do ângulo de visada, que em algumas cenas, podem provocar um desvio de vários graus na temperatura da superfície, não são levados em consideração.

Uma forma de melhorar as estimativas obtidas com o algoritmo SEBAL seria usar a metodologia proposta por Trezza (2002), que sugere a aplicação do balanço hídrico quando há registro de incidência de chuvas nos 5 ou 6 dias que antecedem ao imageamento, caso das imagens de 2010 e 2011, uma vez que, nesses casos, é provável que existam resíduos de umidade do solo. Quando essa situação ocorre, a seleção do pixel quente pode ser comprometida. Esse é um problema recorrente em regiões úmidas, uma vez que o SEBAL foi desenvolvido e validado em condições de clima árido e semiárido. Observa-se que foi a imagem de 2006, sem ocorrência de Zprecipitação nos dias anteriores ao imageamento, que resultou nos erros mais baixos.

É importante citar que os baixos erros relativos obtidos nesta pesquisa não representam uma validação perfeita do SEBAL, uma vez que o próprio método da FAO-PenmanMonteith, usado para validação dos resultados, pode apresentar erros devido a falhas decorrentes de falta de manutenção dos instrumentos. Por outro lado, pode-se afirmar que, no estado atual do conhecimento, não se encontram equações de cálculo da ET, baseadas em dados climáticos, que estimem perfeitamente a ET em todas as condições climáticas devido a simplificações na 
formulação e erros de medição dos dados (Allen et al., 1998). Não obstante, o método da FAO-Penman-Monteith foi elaborado por diversos especialistas e pesquisadores, em colaboração com a Comissão Internacional para a Irrigação e Drenagem e com a Organização Mundial de Meteorologia e, por isso, é considerado o método padrão de estimativa da ETo com dados meteorológicos, na ausência de lisímetros.

\section{CONCLUSÕES}

Os resultados mostraram a capacidade do SEBAL de fornecer a variabilidade espacial dos diferentes componentes do balanço de energia, com capacidade de distinguir diferentes ocupações do solo.

O cômputo do balanço de energia usando o algoritmo SEBAL possibilita observar quantitativamente e espacialmente as formas diferenciadas do uso da radiação líquida pelos diferentes tipos de cobertura do solo.

As estimativas da ET obtidas pelo algoritmo SEBAL apresentaram uma boa concordância com a ETc obtida pelo método da FAO-Penman-Monteith em área de cana-de-açúcar, mostrando a potencialidade da técnica, embora se deva destacar o limitado conjunto de dados coletados in situ para a adequada validação dos resultados. Com dados de altas resoluções temporal e espacial, com uma adequada rede de estações in situ para melhor validar o emprego do algoritmo em escalas operacional e de rotina, pode-se antever que essa importante ferramenta presta-se ao monitoramento de necessidades hídricas de culturas agrícolas, entre outras aplicações.

\section{REFERÊNCIAS BIBLIOGRÁFICAS}

ALLEN, R.G.; PEREIRA, L.S.; RAES, D.; SMITH, M. Crop evapotranspiration - Guidelines for computing crop water requirements - FAO Irrigation and Drainage paper 56. Rome, Italy, 1998.

ALLEN, R. G., TREZZA, R.; TASUMI, M. Surface energy balance algorithms for land. Advance training and users manual, version 1.0, 98p. 2002.

ALLEN, R.; TASUMI, M.; TREZZA, R. Satellite-based energy balance for mapping evapotranspiration with internalized calibration (METRIC) - Model. Journal of Irrigation and Drainage Engineering, v.133, n.395, p.380-394. 2007.

ANDERSON, M.C., ALLEN, R.G., MORSE, A., KUSTAS, W.P. Use of Landsat thermal imagery in monitoring evapotranspiration and managing water resources. Remote Sensing of Environment, v.122, p.1-202. 2012.

ANDRADE, R.G. Aplicação do algoritmo SEBAL na estimativa da evapotranspiração e da biomassa acumulada da cana-de-açúcar. Tese (Doutorado em
Meteorologia Agrícola). Universidade Federal de Viçosa $-\mathrm{MG}, 164 \mathrm{p}, 2008$.

BARR, A.G.; MORGENSTERN, K.; BLACK, T.A.; McGaughey, J.H.; NESIC, Z. Surface energy balance closure by the eddy-covariance method above three boreal forest stands and implications for the measurement of the $\mathrm{CO}_{2}$ flux. Agricultural and Forest Meteorology, v.140, p.322-337. 2006.

BASTIAANSSEN, W.G.M. Regionalization of surface flux densities and moisture indicators in composite terrain, dissertation submitted in partial fulfillment of the requirements for the degree of Doctor of Philosophy in Agricultural Engineering, Wageningen Agricultural University, Wageningen, Netherlands. 1995.

BASTIAANSSEN, W.G.M., MENENTI, M.; FEDDES, R.A.; HOLTSLAG, A.A.M.. A remote sensing surface energy balance algorithm for land (SEBAL). Part. 1: Formulation. Journal of Hydrology, v.212-213, p.198-212, 1998a.

BASTIAANSSEN, W. G. M.; PELGUM, H.; WANG, J.; MA, Y.; MORENO, J. F.; ROENRINK, G. J.; VAN DER WAL, T. A. A remote sensing surface energy balance algorithm for land (SEBAL). Part 2: Validation. Journal of Hydrology, v. 212-213, p.213-229, 1998 b.

BASTIAANSSEN, W.G.M. SEBAL - based sensible and latent heat fluxes in the irrigated Gediz Basin, Turkey. Journal of Hydrology, v.229, p.87-100, 2000.

BASTIAANSSEN, W.G.M.; ALI, S. A new crop yield forecasting model based on satellite measurements applied across Indus Basin, Pakistan. Agriculture Ecosystems \& Environments, v.94, p.321-340, 2003.

BASTIAANSSEN, W.G.M., CHEEMA, M.J.M., IMMERZEEL, W.W., MILTENBURG, I.J., PELGRUM, H. Surface energy balance and actual evapotranspiration of the transboundary Indus Basin estimated from satellite measurements and the ETLook model. Water Resources Research, v. 48, W11512, doi: 10.1029/2011WR010482, 2012.

BEZERRA, B.G.; SILVA, B.B. da.; FERREIRA, N.J. Estimativa da evapotranspiração real diária utilizando-se imagens digitais TM-Landsat 5. Revista Brasileira de Meteorologia, v.23, 305-317, 2008.

Chávez, J.L., Gowda, P.H., Howell, T.A., Garcia, L.A., Copeland, K.S., and Neale, C.M.U. 2012. ET mapping with high resolution airborne remote sensing data in an advective semi-arid environment. Journal of Irrigation and Drainage Engineering, v.138, p.416-423, 2012.

D'ALGE, J. C. L. Cartografia para Geoprocessamento. In: CÂMARA, G.; DAVIS, C. e MONTEIRO, A. M. V. (Ed.). Introdução à Ciência da Geoinformação. São José dos Campos: INPE, 2003. p.6-1 a 6-32. 
Di LONG, D. GAO, Y., SINGH, V.P. Estimation of daily average net radiation form MODIS data and DEM over the Baiyangdian watershed in North China for clear sky days. Journal of Hydrology, v.388, p. 217-233, 2010.

DOORENBOS, J.; PRUITT, W.O. Crop Water Requirements FAO Irrigation and Drainage paper 24. Rome, Italy, 1977.

FIELD, R., O'BRIEN, E.M., WHITTAKER, R.J. Global models for predicting woody plant richness from climate: development and evaluation. Ecology, v.86, p.2263-2277, 2005.

GIONGO, P.R. Estimativa do balanço de radiação com técnicas de sensoriamento remoto e dados de superfície. Dissertação de Mestrado (Mestrado em Engenharia Agrícola) - Universidade Federal Rural de Pernambuco. Departamento de Tecnologia Rural. 92 p. 2008.

GOMES, H.B; SILVA, B.B.; CAVALCANTI, E.P.; ROCHA, H.R. Balanço de radiação em diferentes biomas no estado de São Paulo mediante imagens Landsat 5. Geociências, v.28, p.153-164, 2009.

HAFEEZ, M.M.; CHEMIMY. VAN DE GIESEN N. BOUMAN, B.A. M Field Evapotranspiration in Central Luzon, Philippines, using different sensors: Landsat 7 ETM+, Terra Modis and Aster. In: SYMPOSIUM ON GEOSPATIAL THEORY, Processing and Applications, 2002, Ottawa, Canadá. Anais...Ottawa: , 2002.

HENDRICKS FRANSSEN, H.J.; STOCKLI, R.; LEHNER, I.; ROTENBERG, E.; SENEVIRATNE, S.I. Energy balance closure of eddy-covariance data: A multisite analysis for European FLUXNET stations. Agricultural and Forest Meteorology, v.150, p.1553-1567. 2010.

IRRIGATED CROP MANAGEMENT SERVICE (ICMS). IRES: Irrigation Recording and Evaluation System Training Manual, version 4.01, 2010. 271p.

LANDSAT.ORG. Banco de imagens dos satélites Landsat 4, 5 e 7. Disponível em: <www.landsat.org.> Acesso em: 5 março 2012.

LARCHER, W. Ecofisiologia vegetal. São Carlos: Rima, 2000. $531 \mathrm{p}$.

LIU, W.T.H. Aplicações de sensoriamento remoto. Campo Grande - MS, Ed. UNIDERP, 2007. 908 p.

MATINFAR, H.R. Evapotranspiration estimation base upon SEBAL model and fieldwork. Annals of Biological Research, v.3, p.2459-2463. 2012.

MENDONÇA, J.C. Estimativa da evapotranspiração regional utilizando imagens digitais orbitais na região Norte Fluminense. Tese (Doutorado em Produção Vegetal), Universidade Estadual do Norte Fluminense Darcy Ribeiro, Rio de Janeiro, 145p., 2007.

MENEZES, S.J.M. da C., SEDIYAMA, G.C.; SOARES, V.P., CLERIANI, J.M., ANDRADE, R.G. Estimativa dos componentes do balanço de energia e da evapotranspiração em plantios de eucalipto utilizando o algoritmo SEBAL e imagem Landsat 5 - TM. Revista Árvore, v.35, n.3, p.649-657, 2011.

NAGLER, P. L.; SCOTT, R. L.; WESTENBURG, C.; CLEVERLY, J. R.; GLENN, E. P.; HUETE, A. R. Evapotranspiration on western U.S. rivers estimated using the Enhanced Vegetation Index from MODIS and data from eddy covariance and Bowen ratio flux towers. Remote Sensing of Environment, v. 97, p. 337-351, 2005.

O'BRIEN, E.M. Biological relativity to water-energy dynamics. Journal of Biogeography, v.33, p.1868-1888, 2006.

O'BRIEN, E.M., FIELD, R., WHITTAKER, R.J. Climatic gradients in woody plant (tree and shrub) diversity: waterenergy dynamics, residual variation, and topography. Oikos, v.89, p.588-600, 2000.

OLIVEIRA, L.M.M. Estimativa da evapotranspiração real por sensoriamento remoto na bacia do rio Tapacurá PE. Tese de Doutor em Tecnologia Ambiental e Recursos Hídricos. Recife - Brasil, 136, 2012.

PAIVA, C.M. Estimativa do Balanço de Energia e da Temperatura da superfície via satélite NOAA-AVHRR. Tese Doutor em Ciências em Engenharia Civil. Rio de Janeiro - Brasil, 248p, 2005.

PEREZ, P. J.; CASTELLVI, F.; MARTÍNEZ-COB, A. A simple model for estimating the Bowen ratio from climatic factors for determining latent and sensible heat fluxes. Agricultural and Forest Meteorology, v. 148, p. 25-37, 2008.

ROERINK, G.J.; SU, Z.; MENENTI, M. S - SEBI: A Simple Remote Sensing Algorithm to Estimate the Surface Energy Balance. Physical Chem. Earth (B), v.25, n.2, p.147-157, 2000.

SANTOS, F.A.C. Alterações no Balanço Radiativo e Impactos Climáticos Decorrentes do Uso da Terra no Estado de São Paulo. Dissertação Mestre em Meteorologia. Campina Grande - PB, 78p., 2010.

SANTOS, C.A.C. Análise das necessidades hídricas da vegetação Tamarisk Através da razão de Bowenn e do modelo SEBAL. Revista Brasileira de Meteorologia, v.26, n.1, 85-94, 2011.

SANTOS, C. A. C.; BEZERRA, B. G.; SILVA, B. B. da; RAMANA RAO, T. V. Assessment of daily actual evapotranspiration with SEBAL and S-SEBI algorithms in cotton crop. Revista Brasileira de Meteorologia, v.25, n.3, 383-392, 2010.

SILVA, B. B. da; LOPES, G. M.; AZEVEDO, P. V. Balanço de Radiação em Áreas Irrigadas Utilizando Imagens Landsat 5-TM. Revista Brasileira de Meteorologia, v.20, n.2, p.243-252. 2005.

SILVA, B. B. da.; BEZERRA, M. V. C. Determinação dos fluxos de calor sensível e latente na superfície utilizando imagens 
TM - Landsat 5. Revista Brasileira de Agrometeorologia, 14, 1-10. 2006.

SILVA, B. B. da; MENDONÇA, R. R. O.; SILVA, S. T. A.; FERREIRA, R. C. Mapeamento do Albedo de Áreas Heterogêneas do Estado do Ceará com imagens TM-Landsat 5. Revista de Geografia, v.25, n.2, p.33-52. 2008.

SILVA, B. B. da; BRAGA, A. C.; BRAGA, C. C. Balanço de radiação no perímetro irrigado São Gonçalo - $\mathrm{PB}$ mediante imagens orbitais. Revista Caatinga, v. 24, n. 3, p. 145-152, 2011.

TASUMI, M.; ALLEN, R.G.; TREZZA, R.; WRIGH J.L. Satellite-Based Energy Balance to Assess Within-Population Variance of Crop Coefficient Curves. Journal of Irrigation an Drainage Engineering, p.94-108. 2005.

TASUMI, M.; ALLEN, R.G.; TREZZA, R. At-Surface Reflectance and Albedo from Satellite for Operational Calculation of Land Surface Energy Balance. Journal of hydrologic engineering, v.13, n.2, p.51-63. 2008.

TEIXEIRA, A.H. de C.; BASTIAANSSEN, W.G.M., AHMAD, M.D.; BOS, M.G. Reviewing SEBAL input parameters for assessing evapotranspiration and water productivity for the Low-Middle São Francisco River basin, Brasil Part A: Calibration and validation. Agricultural and Forest Meteorology, v.149, p.462-476, 2009.
TIMMERMANS, W.J.; MEIJERINK, A.M.J. Remotely sensed actual evapotranspiration: implications for groundwater in Botswana. International Journal of Applied Eath Observation, v.1, Issue 3-4, p.222-233, 1999.

TREZZA, R. Evapotranspiration using a satellite-based surface energy balance with standardized ground control. Thesis (Doctor of Philosophy in Biological and Agricultural Engineering). Utah State University. Logan, Utah. 247p. 2002.

WANG, J., KIMURA, R.; BASTIAANSSEN, W. Monitoring ET with Remote Sensing and the Management of Water Resources on a Basin Scale, 11th CEReS International Symposium on Remote Sensing, Chiba, Japan. 2005. 